TFE STUDY OF DEFECTS AND RADIATION DAMAGE IN SOLIDS

BY FIELD-IOH AND ATOM-PROBE MICROSCOPY

\section{MASTER}

David N. Seidman

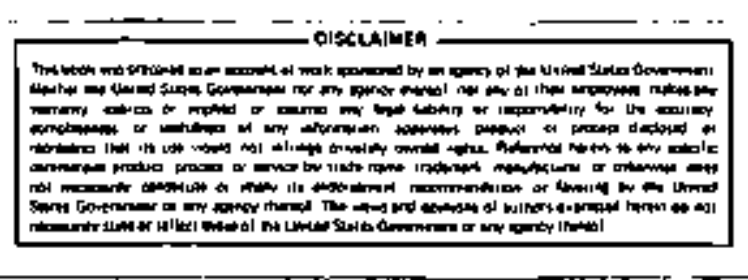

Cornell University

Ithaca, New York 14853

June 1979

Report $\$ 4106$

Frepared for

THE U.S. DEPARTMENT OF EHARGY UMDER

COMTRACT HO. EY-76-S-02-3158.*000.

DISTHIEUTION OF THIS DOCUMENT IS UNCUMTYS 


\section{DISCLAIMER}

This report was prepared as an account of work sponsored by an agency of the United States Government. Neither the United States Government nor any agency Thereot, nor any of their employees, makes any warranty, express or implied, or assumes any legal liability or responsibility for the accuracy, completeness, or usefulness of any information, apparatus, product, or process disclosed, or represents that its use would not infringe privately owned rights. Reference herein to any specific commercial product, process, or service by trade name, trademark, manufacturer, or otherwise does not necessarily constitute or imply its endorsement, recommendation, or favoring by the United States Government or any agency thereof. The views and opinions of authors expressed herein do not necessarlly state or reflect those of the United States Government or any agency thereof. 


\section{DISCLAIMER}

Portions of this document may be illegible in electronic image products. Images are produced from the best available original document. 


\title{
THE STUDY OF DEFECTS AND RADIATION DAMAGE IN SOLIDS \\ BY FIELD-IOM AND ATOM-PROBE MICROSCOPY
}

\author{
by \\ David N. Seidman \\ Cornell University, Department of Materials Science and Engineering \\ and the Materiais Science Center, \\ Bard Hall, Ithaca, New York 14853
}

\begin{abstract}
A brief review is presented of: (1) the basic physical principles of the field-ion and atom-probe microscopes; (2) the many applications of these instruments to the study of defects and radiation damage in solids; and (3) the application of the atow-probe field-ion microscope to the study of the behavior of implanted ${ }^{3}$ He and ${ }^{4}$ He in tungsten. The paper is hearily referenced so that the reader can pursue his specific research interests in detail.
\end{abstract}




\section{THTRODUCTION}

In this short paper an attempt is made to introduce the reader to the basic physical ideas involved in the field-ion and atom-probe field-ion microscope techniques (52), and to the applications of these techniques to the study of defects and radiation damege in solids (\$3). The final section (54) discusses, in prêtis form, the application of the atom-probe field-ion microscope to the study of the behavior of implanted ${ }^{3}$ He and ${ }^{4}$ He atoms in tungsten. The paper is heavily referenced so that the reader can pursue his specific research interests in detail.

\section{GENERAL BACKGROUND MATERIAL}

The invention of the field-ion wieroscope (FIM) and the atom-probe FIM by Muller ${ }^{(1,2)}$ has provided the experimentalist with tools which allow both the direct observation of all the conmon defects (polnt, line and planar) on an atomic scale and the simultaneous determination of cherical effects on an atomic scale (the minimum detectable mass is the mass of a single atom).

The atomic structure of the direct lattice is observed for those atons which lie on the surface of a sharply pointed (w200 to $500 \mathrm{~A}$ in diameter) FIM specimen; the area imaged is $w 10^{-10}$ to $10^{-11} \mathrm{~cm}^{2}$. The information concerning the positions of the atoms is carried to a phosphor screen or a channel electron multiplier array $(3,4)$ by an imaging gas which is typically helium or neon. The imaging gas atoms are ionized, by a tunneling mechanism, in the high local electric fields (w.5 $\mathrm{V} \mathrm{A}^{-1}$ to ionize a heliun aton) that exist at the site of individual atoms as result of a positive potential applied to a sharply pointed FIM specimen. (5) The positively-charged ions are repelled from the spectmen and then travel along the electric field lines to the phosphor screen which is at earth potential; typically the phosphor screen is at a distance of between 4 to 10 cn from the FIM specimen. The image formed of the atoms on the surfece of 
the FIM specinen, in the above manner, constitutes a point projection inage with sufficient magnfication to resolve individual atoms.

The interior of the specinen can be examined employing the field-evatoration process. The latter process consists of increasing the electric field to a value such that the potential energy curve of an ion on the surface of the specimen (this statement assumes that the state in which the metal atoms exist on the surface of the specimen is the ionic state) is deformed by the applied field to form (Schottky hump. (6) The lons then evaporate (sublime) by either jumping over this small sehottky hump or by tunneling through it; this process is called fleld desorbtion or field eveporation. The field evaporation process can be contralled by applying the positive potential in the form of short (1 to $10 \mathrm{msec}$ in width) high-voltage pulses. This latter technique is called pulse field efaporation; it is possible by this technique to dissect an atomic plane one or two atoms at a time. Thus, the atoms contained within the interior of the specimen can be 1uaged, albeit at the surface, at a rate which is deternined by the experimentalist. In practice one can examine $\neq 10^{-16}$ to $10^{-17} \mathrm{~cm}^{3}$ of material, during the course of one experiment, via the pulse field evaporation technique. At Cornell we have developed semi-automated techniques for the process of applying the field evaporation pulse in congudetion with the simulaneous recording of large numbers of frames of $35 \mathrm{~mm}$ cine film [(15 to 30$) \times 10^{3}$ frames per day] as vell as developing techniques for the scanning of this film. (T) It is clear, with the advantage of hindsight, that these two steps were essential to the successful application of the FIM technique to problems in the field of radiation danage. The invention (2) of the time-of-flight (TOF) atom-probe FIM has provided us with a. unique instrument for the study of the interaction of inpurity atoms or alloying elements with point, liae or planar defects. The TOF atom-probe FIM (hereafter called an atom probe) consists of an FIM combined with a special TOF mess spectrometer. This spectrometer allows the investigator to identify chemically any atom that appears in an FIM imege. Thus, it is now possible to 
II. Volume Change of Migration $\left(\Delta v_{1 i}^{\text {mI }}\right)$ of SIAs

a. Measured $\Delta v_{1 i}^{m}$ for the SIA in $W, P t$ and Mo in detail. Experiments were also performed on $\mathrm{Ni}_{4}$ Mo and $\mathrm{Pt}_{3} \mathrm{CO}$ but in less detail.

b. For further details see reference numbers 18, 19, 27, 28, 31, 37, $38,39,40,41$.

III. Binding Enthalpy of an SIA to a Solute Atom $\left(\Delta h^{b}\right)$

a. Measured $\Delta \mathrm{h}^{\mathrm{b}}$ by determining a dissociation enthalpy $\left(\Delta \mathrm{h}^{\mathrm{d}}\right)$ and then determining $\Delta \mathrm{h}^{\mathrm{b}}$ from the expression $\Delta \mathrm{h}^{\mathrm{d}}=\Delta \mathrm{h}^{\mathrm{b}}+\Delta \mathrm{h}_{\mathrm{li}}^{\mathrm{m}}$. The system Pt (Au) was studied in great detail and two detrspping stages (II and $\mathrm{II}_{\mathrm{C}}$ ) were observed in Stage II.

b. The gystems $W(R e)$ and $W(C)$ were also studied but in less detail.

c. For further details see reference numbers $19,21,33,36,39,40$.

IY. Diffustve Properties of Vacancies

a. Measured ratio of divacancy concentration to monovacancy concentration for one quench temperature in platinum specimens.

b. From (a) It was possible to determine the Gibbs free binding energy $\left(\Delta \mathrm{g}_{2 v}^{\mathrm{b}}\right)$ in platinum.

c. Measured vacancy concentration in tungsten specimens which had been quenched from neer the melting point.

d. The meesurements discussed in (a) to (c) are important for interpreting the high-temperature self-diffusion data by point-defect mechanisms.

e. For further details see reference numbers 18, 42, 43, 44, 45, 46.

V. Diffusive Properties of Geses in Metals
a. Diffusion of ${ }^{3} \mathrm{He}$ and ${ }^{4} \mathrm{He}$ in tungsten and platinu.
b. Diffusion of $1_{H}$ and ${ }^{2} H$ in tungsten.
c. For further details see reference numbers $47,48,49,50,51,52$. 
VI. Range Proriles of Low-Energy Implanted Gases in Metals

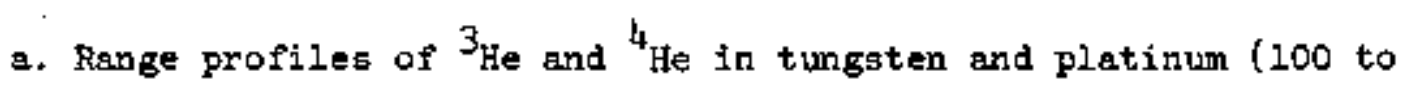
1500 eV singly-charged ions).

b. Range profiles of ${ }^{1} \mathrm{H}$ and ${ }^{2} \mathrm{H}$ in tungsten.

c. For further details see reference numbers $47,48,49,50,51,52$.

VII. Polnt-Defect Structure of Depleted zones: The Primary State of

Radiation Damage

a. Depleted tones in ion-irradiated metals [W, $\mathrm{Pt}, \mathrm{Pt}\langle\mathrm{A} u\}]$

(1) Dimensions of depleted zones (DZs)

(i1) Wumber of vacancies per DZ.

(iii) Yacency concentration within DZs

(iv) The distribution of lst-nearest-nefghbor vacancy clusters

(v) The radial distribution function (RDF) for the vacancies out to 9 th-nearest-neighbor

b. Effect of projectile mass $\left(M_{1}\right)$ on the structure of DZs at constant projectile energy

c. Effect of $M_{1}$ on the structure of DZs at constant reduced energy ( $\varepsilon$ )

d. For further details see reference numbers 18, 20, 21, 49, 53, 54 , $55,56,57$.

VIII. Damage Profiles

a. $\mathrm{Ne}^{+}$(250 to $2500 \mathrm{eV}$ ) irradiated $\mathrm{Ni}_{4} \mathrm{Mb}$ and $\mathrm{Pt}_{3} \mathrm{Co}$ (order-disorder alloys). Damage profiles determined by measuring the change in the Bragg-Williams long-range order parameter(s) as a function of depth.

b. $30 \mathrm{keV} \mathrm{\textrm {H } ^ { + }}, \mathrm{Cr}^{+}$or $\mathrm{Mo}^{+}$Irradiated Tungsten.

c. For further details see reference numbers $38,49$. 
IX. Sputtering of Surfaces

a. The sputtering of a inetal surface is the result of the interBection of a collision cascede with it. In this work we compared the vacancy structure of depleted zones, produced by 30 keV $\mathrm{W}^{+}, \mathrm{MO}^{+}, \mathrm{Cr}^{+}, \mathrm{Cu}^{+}$or $\mathrm{Ar}^{+}$jons, that were found to have intersected the surface of a tungsten FIM specimen with the depleted zones found in the bulk of the spectmen.

b. For further details see reference number 57 .

X. Voids in Meutron-Irradiated Metals [Mo, Mo(Ti), Fe(Cu)]

a. Void number density: need a number density of $\mathrm{k}_{10} \mathrm{O}^{1 \mathrm{~cm}^{-3}}$ in order to be able to make measurements.

b. Void size distribution: same comment as in X.a. applicable.

c. Direct observation of segregation.

d. For further details see reference numbers $58,59,60$.

XI. Distribution of SIAs in the Primary Damage State

a. SIA digtribution in ion-irradiated tungsten $\left(30 \mathrm{keV} \mathrm{W}^{+}, \mathrm{Mo}^{+}, \mathrm{Cr}^{+}\right)$.

b. Range of replacement collision sequences. (RCSs)

c. For further details see reference numbers 53,61 .

4. RANGE PROFILES OF LOW-ENERGY ( 100 to $1500 \mathrm{eV}$ ) IMPLANTED ${ }^{3} \mathrm{He}$ APD ${ }^{4}$ He ATOMS AND THE DIFFUSIVITY OF ${ }^{3}$ He AND ${ }^{4}$ He IM THASTEN

\subsection{General Background}

Current interest in the fundsunental properties of helium in metals has been generated by the materials problems associated with the development of the liquid-metal fast-breeder reactor ${ }^{(62)}$ and the controlled thermonuclear reactor. (63) However, because of a lack of appropriate experimental techniques the investigations of the range of low-energy (<l kev) implanted He fons and 
the diffusivity of He in metals have been largely theoretical $(64-66)$ Measurement of the range profiles of implanted He lons have been confined to energies (67) $>1 \mathrm{keV}$; furthermore, the measurement of both the range profiles of implanted He and the diffusivity of He in metals heve relied exclusively on the trapping of He at lattice defects introduced as a result of heavy-ion irradiation.

The accomplishments of our research on helium implanted in tungsten were: (1) the establishment of the ebility of the atom-probe FIM to detect either implanted ${ }^{3}$ He or ${ }^{4}$ He atoms retained in a perfect (i.e., totally defectfree) lattice; (2) the detection of the presence of an isolated and inmobile ${ }^{3} \mathrm{He}$ or ${ }^{4} \mathrm{He}$ atom $1 \mathrm{n}$ a perfect tungsten lattice; (3) the measurement of the range proriles of low-energy (100 to $1500 \mathrm{ev}$ ) implanted ${ }^{3} \mathrm{He}$ or ${ }^{4}$ He atons in a perfect tungsten lattice; and (4) the meesurement of the aiffusivities of ${ }^{3} \mathrm{He}$ and ${ }^{4}$ He in a perfect tungsten lattice.

The basic physical ideas involved in the experimental procedures are illustrated sequentially in Fig. 1. A single-crystal W FIM specimen, at an irradiation temperature $\left(\mathrm{T}_{1}\right)$, was irradiated in situl with ${ }^{3} \mathrm{He}^{+}$or ${ }^{4} \mathrm{He}^{+}$ions perallel to the [110] airection as shown in Fig. 1(a). To study the diffusional behavior of either ${ }^{3}$ He or ${ }^{4}$ He in tungsten it was necessary to implant the helium under the condition of no radiation damage. For example, a $300-\mathrm{V}^{4} \mathrm{He}$ atom can transfer a maximum energo of vas $\mathrm{eV}$ to a W atom in a head-on two-body elastite collision. Since the minimum diaplacement energy for the production of a stable Frenkel peir in $\mathrm{W}$ is $\approx_{42} \mathrm{eV}^{(69)}$, no self-interstitial atoms (SIA's) or vacaneies are created at an Implantation energy of 300 ev for elther ${ }^{3} \mathrm{He}$ or ${ }^{4} \mathrm{He}$. Thus for the diffusion experiments a standard implantation energy of $300 \mathrm{eV}$ was employed. With no SIA's or vacancies present to act as trapping centers, implanted ${ }^{3} \mathrm{He}$ or ${ }^{4} \mathrm{He}$ atoms can remain in the specimen only if ${ }^{3} \mathrm{He}$ or ${ }^{4} \mathrm{He}$ is imobize at $\mathrm{T}_{i}$. Thus, the state of the $W$ specimen after an implantation consisted of immobile 
interstitial ${ }^{3}$ He or ${ }^{4}$ He atoms implanted in a perfect 4 lattice with a depth distribution that was detergined solely by the range profile of the low-energy 1ons. Hext the specimen was andyzed chemically, by the etom-probe technique, at a standard reference temperature $\left(T_{r}\right)$, where $T_{r} \leq T_{1}$, and a ${ }^{3}$ He or ${ }^{4} H e$ integrad profile was plotted as shown in Fig. $1(\mathrm{~b})$; this was an integral profile since it measurea the cumulative number of ${ }^{3}$ He or ${ }^{4}$ He atoms as a function of the cumulative number of $\mathrm{w}$ atoms (depth) from the irradiated surface. The depth acale was converted from cumulative number of $\mathbf{H}$ atoms to angstroms from the neasured number of W atoms per (110) plane contained within the cylindrical element samples; see Fig. 1(a). Finally the ${ }^{3}$ he or ${ }^{4}$ He range profile, Fig. $1(0)$, may be constructed by taking the first derivative of the integral profile shown in Fig. 1(b); or alternatively by plotting a frequency distribution diagram.

A novel technique for the determination of an absolute depth scale vas developed; F1g. 2 schematically illustrates the method. Luring the atom-probe analysis the specimen was oriented and the magnirication adjusted so that only the central portion of the W(110) plane was ebemically analyzed. The specimen was then pulse field evaporated through the repeated application of high-voltage pulses. Three successive stages in the pulse field evaporation of one (110) plane are indicated in Fig. 2(e). As the plane was pulsed, field-evaporated atoms were detected as indicated by the positive slope in Fig. $2(b)$. When a plane ras completely evaporated the slope of the curve in Fig. $2(b)$ returned to zero. Therefore the removal of one (110) plane resulted in a single-step increase in the plot of the number of $W$ atoms detected versus the number of field-evaporation pulses applied to the specimen. Since the $W$ lattice was employed as a depth marker, the absolute depth of each implanted ${ }^{3}$ He or ${ }^{4}$ He atom from the initial irradiated surface was measured to within one (110) interplanar spacing $\left(n_{2} .24 \mathrm{~A}\right)$ 
independent of the total depth of enalysis. Thus the spatial depth resolution of the atom-probe techníque is limited solely by the interplanar spacing of the region being analyzed.

4.2. Integral and range profiles of low-energy implanted ${ }^{3}$ He and ${ }^{4}$ tie atoms In this section we present a number of integral profiles and range proriles for both ${ }^{3}$ He and ${ }^{4}$ He which had been implanted in tungsten at $60 \mathrm{~K}$. The tern integral profile reflects the manner in which the data was recorded [see. $\left.f^{\prime} \mathrm{g} . \mathrm{l}(\mathrm{b})\right]$, whereas the range profile was constructed by plotting a frequency distribution diagram from the integral profile [see fig. I(c)]. The range profile can also be obtained by drawing a smooth curve throuth the Integral profile and taking tḥe first derivative of this curve. In all cases we have obtained the range profile by the former rather than the latter tachnique.

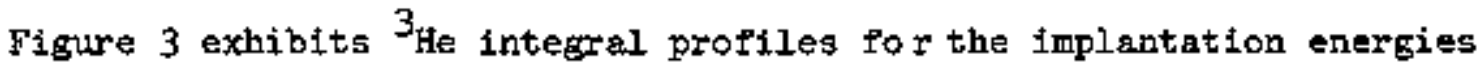
100 , 500 and $1500 \mathrm{eV}$; the $100 \mathrm{eV}$ profile is a composite of two integral profiles each with e dose of $4.7 \times 10^{15}$ ion $\mathrm{cm}^{-2} ;$ both the 500 and $1500 \mathrm{eV}$ integral profiles were obtained after implanting to a dose of $3 \times 10^{15}$ ion $\mathrm{cm}^{-2}$. In fig. 4 we show a composite range profile for $300 \mathrm{eV}^{3}$ He lons; this range profile was constructed from seven integral profiles and includes a total of $385{ }^{3}$ He events; the values of the mean range $(\bar{x})$ and the stragsling $(\Delta x)$ are 54.9 and $41.5 \AA$ respectively.

Figure 5 exhiblts 4 He integral profiles for the implanation energies 150, 500 and $1000 \mathrm{eV}$; the $150 \mathrm{eV}$ data consists of a single integral profile for a specimen that had been implanted to a dose of $3 \times 10^{15}$ ion $\mathrm{cm}^{-2}$; the $1000 \mathrm{eV}$ data is for a single integral profile for a specimen that had received a dose of $4 \times 10^{15}$ ion $\mathrm{cm}^{-2}$. In fig. 10 we show a composite range profile for a $1000 \mathrm{eV}$ ${ }^{4}$ Be implantation; this range profile was constructed from three integral range profiles and includes a total of 147 the events; the values of $x$ and $\Delta x$ are 133 ana 104.2 A respectively. 
All of the ${ }^{3}$ He and ${ }^{4}$ He integral profiles exhibited positive skewness as expected for low-energy irradiations (Biersack and Haggmark ${ }^{(70)}$ ); this implied that the mean range (7) was greater than the most probable range (or mode) and that the majority of the large devietions were to the right (positive) side of $\bar{x}$. The coefficient of skewnegs is related to the third moment about $\bar{x}$ and is given (Parratt ${ }^{(71)}$ ) by: Coefficient of Skewness $=\frac{\sum_{i=1}^{\mathfrak{n}}\left(x_{i}-\bar{x}\right)^{3}}{N(\Delta x)^{3}}$,

where $x_{i}$ is the measured depth of the $1^{\text {th }}$ detected helium aton fron the initial irradiated surface, $N$ is the total number of helium events detected and $\Delta x$ is the standard deviation or straggling.

The values of $\overline{\mathbf{x}}$ and $\Delta x$ were celculated directly from the integral profiles for the ${ }^{3} \mathrm{He}$ and ${ }^{4} \mathrm{He}$ implantations. The values $\bar{x}$ and $\Delta x$ were referred to as uncorrected quantities. The reason for this is that $\bar{x}$ and $\Delta x$ must be corrected for the following systematic errors: (1) the random arrival of helium atoms at the surface of the specimen, from the residual pertial pressure of helium, during the atom-probe anelysis of the Irradiated specimen; and (2) the effect of the rinite eurvature of the FIM tip. A detailed anglysis of the above effects is given elsewhere (Amano, Wagner and Seldman (72), where it was shown that the corrections to $\bar{x}$ and $\Delta x$ were very minimal in our experiments. Thus we shall not enploy the word uncorrected any further in this peper.

Figure 7 exhibits $\bar{x}$ (in $A$ ) versus the incident ion energy (in ev) for both the ${ }^{3}$ He (solid black elrcles) and the ${ }^{4}$ He (open circles) implantations. The total length of each error oir is two standard deviations in the mean ( $\left.\Delta x_{m}\right)$, i.e., plus or minus one $\Delta x_{m}$. The quantity $\Delta x_{\text {ml }}$ is given by:

$$
\Delta \mathrm{x}_{\mathrm{m}}=\Delta \mathrm{x} / \sqrt{\mathrm{t}}
$$


where $\mathrm{N}$ was the total number of helium events detected at a particular incident ion energy for the compogite profile. Figure 7 clearly show that the quantity $\Delta x_{m}$ was negligibly small when $t$ exceeded 50 events. The smallest sample size was for the $100 \mathrm{eV}^{4}$ He implantation where $\mathrm{s}$ was equal to 21 events. In this case $\Delta x_{\text {ma }}$ was $3.5 \AA$ and the fractional standard error $\left(\Delta x_{\text {th }} / \tilde{x}\right)$ was 0.19 . This was the only data point that laid slightly below the smooth line that passed through all the other data points for the "He inplantations.

The results presented in $\mathrm{fig} .7$ show that $\bar{x}$ for both ${ }^{3}$ He and ${ }^{4}$ He increased monotonically, although not linearly, with increasing incident helium ion energy. Overall, for both ${ }^{3} \mathrm{He}$ and ${ }^{4} \mathrm{He}$, the value of $\bar{x}$ increased from 18.7 to $194.9 \AA$ as the incident ion energy was increased from 100 to $1500 \mathrm{eV}$. For an incident helium ion energy of less than $600 \mathrm{eV}$ the $\bar{x}^{\prime} s$ for ${ }^{3}$ He were greater than the $\bar{x}^{\prime} s$ for ${ }^{4}$ He; this indicated that ${ }^{3}$ He penetrated more deeply into the lattice, on the average, than ${ }^{4}$ He. This is the result expected for a lighter species implanted in an amorphous solid. At incident helium ion energies greater than $600 \mathrm{eVt}$ the $\bar{x}$ 's for ${ }^{4}$ He exceeded the $\bar{x}$ 's for ${ }^{3}$ He. A detalled discussion of these effects is given elsewhere (Amano, Wagner and Seidman (T2)).

Figure $B$ displays $\Delta x$ as a function of the incident helium ion energy for both ${ }^{3} \mathrm{He}$ and ${ }^{4} \mathrm{He} ; \Delta x$ is very commonly known as the straggling, since it determines the with of the range profile. The length of each error bar in fig. $B$ is equal to two universe standard deviations in the sample standard deviation $\left(\Delta x_{s}\right), 1 . e$. , plus or minus one $\Delta x_{s}$. The quantity $\Delta x_{s}$, for a normal distribution, is given by (Parratt $(71)$ )

$$
\Delta x_{5}=\Delta x / \sqrt{2 H}
$$

We have used eqn. (3) to obtain approximate qalues of $\Delta x_{g}$ for our range profiles which are actually skewed from a normal distribution. It is seen from fig. 8 that for the sample sizes we employed the values of $\Delta x_{s}$ were all rather small. 
For both ${ }^{3}$ He and ${ }^{4}$ He the value of $\Delta x$ increased monotonically, although not linearly, with increasing incident helium ion energy (see fig. 8). The quantity $\Delta \times$ ranged from 16 to $124 \AA$ as the incident helium ion energy was increased trom 100 to $1500 \mathrm{eV}$. At an incident helium ion eneres of $2300 \mathrm{eV}$ the two curves crossed one another and the $\Delta x^{\prime}$ 's for 'He were greater than those for ${ }^{3}$ He. This indicated that as the iacident ion energy was increased the ${ }^{4}$ He was distributed in space, both wider and deeper than ${ }^{3}$ He.

Figure 9 exhibits the relative variance $\left[(\Delta x)^{2} /(\bar{x})^{2}\right]$, of the ${ }^{3}$ He and ${ }^{4}$ He range profiles, as a runction of the incident helium ion energg (in ev). Within the scatter of the data the quantity $(\Delta x)^{2} /(\bar{x})^{2}$ for ${ }^{3}$ He exhibited a constant value of 20.47 and the same quantity for ${ }^{4}$ He was 20.61 . Thus in the energy range 100 to $1500 \mathrm{eV}$ the value of $(\Delta x)^{2} /(\bar{x})^{2}$ for ${ }^{4}$ He was greater than for ${ }^{3} \mathrm{He}$. This slearly indicated that the ${ }^{4}$ He was distributed more broadly in space than was ${ }^{3} \mathrm{He}$. 4.3. Detection of possible radiation damage in the case of the 300 eV helium implantations.

In order to establish that the ${ }^{4}$ He detected in the case of the 300 eff implantation experiment was not trapped at structural defects in the w Iattice, the following isochronal recovery experiment was performed. A W specimen was irradieted along the [110] direction tith 300-eV ${ }^{4} \mathrm{He}^{+}$ions at w30 $\mathrm{K}$. After the

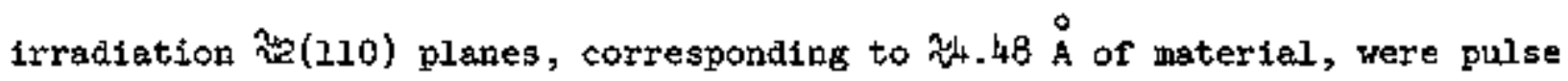
field evaporated from the specimen. This procedure removed the sputtered surface end restored the surface to a nearly perfect state. The specimen was then warmed isochronally from 330 to $90 \mathrm{~K}$ at a rate of $2.5 \mathrm{~K} \mathrm{~min}^{-1}$, while the FIM Image was photographed at a rate of two $35-\mathrm{m}$ cine frames $\sec ^{-1}$. Wo SIA contrast effects were observed during this experiment indicating that no SIA's crossed the surface of the FIM specimen. Our previous work ${ }^{(73)}$ denonstrated that if SIA's were present they would have appeared throughout the entire range of 38 to $90 \mathrm{~K}$. The specimen was then dissected by the pulse fleld-evaporation technique and was examined 
for point defects. The density of point defects was determined to be $<8 \times 10^{-4}$ (atomic fraction); their depth distribution was not related to the "He integral profiles. These results constitute conclusive evidence that the ${ }^{4}$ He was not trapped at SIA's or vacancies. This Indicated that the 4 He atoms were located in the interstices of the lattice and that they were immobile in tungsten at 60 . 4.4. The diffusitities of ${ }^{3}$ He and ${ }^{4}$ He in tungsten.

The temperature at which the interstitial ${ }^{4}$ He atoms became mobile in $W$ was determined by implanting ${ }^{4} \mathrm{He}$ in an FIM specimen at different $T_{i}{ }^{\prime} s$ and then enalyzing at $T_{r}=60 \mathrm{~K}$. The ${ }^{4} \mathrm{He}$ integral profile determined at $T_{r}$ was independent of $T_{i}$ oaly if the ${ }^{4}$ He was imobile at all values of $T_{1}$. However, when $T_{i}$ was above the temperature at which the ${ }^{4}$ He interstitials becane mobile, the ${ }^{4}$ he implanted during the Irradiation diffused to the surface of the Fid specimen and entered the gas phase. Therefore a sharp decrease in the measured He concentration was expected as $T_{i}$ tos increased (see fig. 1 ). Since only $T_{i}$ was varied, signjficant changes in the integral profile eould only be attributed to a sharp increase in the mobility of the interstitial ${ }^{4}$ He atons at $T_{1}$. A dramatio change in the integral profile was observed upon increasing $T_{i}$ from 90 to $110 \mathrm{~K}$; thus indicating that interstitial $4 \mathrm{He}$ atons were immobile at $90 \mathrm{~K}$ but were highly nobile at $120 \mathrm{~K}$. By employing a diffusion tabdel, a value of the enthalpy change of migration $\left(\Delta \mathrm{hl}_{\mathrm{He}}^{\mathrm{m}}\right)$ of 0.24 to $0.32 \mathrm{eV}$ was estimated. The upper and lower limits on ${ }^{4}{ }^{m}{ }_{4}$ he were deterained by the values of the pre-exponential. factor $\left(D_{0}\right)$ chosen for the calculation of this quantity; the lower lfmit was determined by a $D_{0}$ of $1 \times 10^{-3} \mathrm{~cm}^{2} \mathrm{sec}^{-1}$ and the upper limit by a $D_{0}$ of $1 \times 10^{-2} \mathrm{~cm}^{2} \mathrm{sec}^{-1}$. The diffusivity of ${ }^{3}$ He in tungsten vas determined by actually following the isothermal recovery of $300 \mathrm{eV}$ implantation profiles which had been Implanted at $90,95,98,100$ and $110 \mathrm{~K}$. The diffusion equation was solved with appropriate 
initial and boundery conditions, to describe the diffusion of ${ }^{3}$ He out of an FIM tip under isothermal conditions. The fit of the experimental isothergin recovery data to the solution of the diffusion equation yielded the diffusivity of ${ }^{3}$ He as a function of temperature. The results of this work are shown in fí. 10. It is seen that the data is best described by the expression

$$
D\left({ }^{3} \text { He }\right)=(5.4-3.8) \times 10^{-3} \exp \left[\frac{-0.28 \pm 0.01 \mathrm{eV}}{\mathrm{kT}}\right] \mathrm{cm}^{2} \sec ^{-1}
$$

Thus within the measured experinental uncertainties the Ah's for ${ }^{3} \mathrm{He}$ and ${ }^{4} \mathrm{He}$ In tungsten are identical. For further details on $3_{\text {He }}$ in tungsten see Amano and Seidman. (50)

\section{ACKNOWLEDGEMENTS .}

This work was supported by the U.S. Department of Energy. Additional support was received from the National science Foundation through the use of the technical facilities of the Materials Science Center at Cornell University. I wish to thank my co-workers Drs. J. Amano and A. Wagner for permission ot present results (see 54 ) in adrance of more formal publication. 


\section{REFEREHCES}

1. E.W. Mïller, Z. Physik 131,136 (1951).

2. B.W. Müller, J.A. Panitz and S.B. McLane, Rev. Sci. Instrum. 39, 83 (1968).

3. F.J. Turner, P. Cartwright, M.J. Southon, A. van Dostrom and B.W. Weniey, J. Sci. Instrum. $\underline{2}, 731$ (1969).

4. S.S. Brenner and J.T. MeKinney, Surface Sci. $\underline{23}, 88$ (1970).

5. B.W. Mïller and T.T. Tsong, Field-Ion Microscopy (American Elsevier, Hew York, 1969), Chapt, II.

6. E.W. Müiler and T.T. Tsone, Field-Ion Microscopy (American Elsevier, New York, I969), Chapt. III.

T. R.M. Scanlan, D.L. Styris, D.H. Seldman and D.G. Ast, Cornell haterials Science Center Report No. 1159 (1969).

8. W.P. Poschenrieder, Int. J. Mass Spectrom, and Ion Phys. 2, 357 (1972).

9. E.W. Nüller and S.v. Krishnaswamy, Rev. Sci. Instrum. 45, 1053 (1974).

10. R. Gomer, Field Emission and Field-Ionization (Harvard University Press, Cambridge, Massachusetts, 1961).

21. Field-Ion Microscopy, edited by J.J. Hren and S. Ranganathen (Plenum Press, New York, 1968).

12. Applications of Field-Ion Microscopy, edited by R.F. Hochman, E.H. Mïler and B. Ralph (Advanced Research Projects Agency, ARDA order No. 878 and the Georgia Institute of Technology, 1969).

13. K.N. Bowkett and D.A. Smith, Field-Ion Microscopy (American Elsevier, Hew York, $1970)$.

14. Fiela-Ion, Field Enisston Microscopy and Reiated Topics, special issue of Surface Science $\underline{23}, 1$ (1970).

15. E.W. Müller and T.T. Tsong, In Progress in Surface Scfence, edited by S.G. Davison (Pergamon Press, oxford, 1973), Vol. 4, Fart I, pp. 1-139. 
16. J.A. Panitz, in Progress in Surface Science, edited by S.G. Davison (Perganon Press, oxford, 1978), Vol. 8, pp. 219-62.

17. Proceedings of the Int. Symp. on Applicetion of FIM to Hetallurgy, edited by R.R. Hasiguti, Y. Yashiro and N. Igata (Dept. of Metallurgs and Materials Science, Unir. of Tokyo, Tokyo, Japan, 1977).

18. D.N. Seidman, J. Phys. F: Metal Phys. 3, 393 (1973).

19. D.H. Seldman, K.L. Wilson and C.H. Nielsen, in Proceedings of the Int. Conf. on Fundamental Aspects of Radiation Damage in Metals, edited by M.T. Robinson and F.W. Young, Jr. (National Technical Information Service, U.S. Dept. of Comnerce, Springfield, Virginie, 1975), pp. 373-96.

20. D.N. Seidman, in Radiation Damage in Metals, edited by N.L. Peterson and S.D. Harkness (American Society for Metals, Hetals Park, ohio, 1976), pp. $28-57$.

21. D. H. Seidman, Surface Sci. 70, 532 (1978).

22. A. Wagner, T.M. Hell and D.N. Seidman, Rev. Sci. Instrum. 46, 1032 (1975).

23. T.M. Hall, A. Wagner, A.S. Berger and D.N. Setaman, Comell Materials Science Center Report No. 2357 (1975).

24. T.M. Hall, A. Wagner, A.S. Berger and D.N. Seidmen, Seripta Met. 10, 4B5 (1976).

25. T.M. Hall, A. Wagner and D.H. Seidman, J. Phys. E: Sci. Instrum. 10, 884 (1977).

26. A. Hagner, T.M. Hall and D.N. Seldman, J. Nue. Hat. 69 \& 70, 532 (1978).

27. R.M. Scanlan, D.I. Styris and D.N. Seldman, Phil. Mag. 23, 1439 (1971).

28. R.M. Scanlan, D.L. Styris and D.H. Seidman, Fhil. Mag. 23, 1459 (1971).

29. P. Pétroff and D.H. Setdman, Appl. Fhys. Lett, 18, 518 (1971).

30. D.N. Seidman and K.H. Lie, Acta Met. 20, 1045 (1972).

31. P. Pétroff and D.H. Sediman, Acta Met. 로, 323 (1973).

32. J.T. Robertson, K.L. Wilson and D.f. Seidman, Phil. Meg. 27, 1417 (1973).

33. D.N. Seidman, K.L. Wilson and C.H. Nielsen, Fhys, Rev. Lett, 35, 1041 (1975).

34. K.L. Wilson and D.H. Seidman, Rad. Effects $\underline{33}, 149$ (1977).

35. D.N. Seidman, Scripta Met. 13, 251 (1979). 
36. X.L. Wilson, M.I. Baskes and D.H. Selaman, Cornell Materials Science Center Report H4055 (1979); subitited to Acta Metallurgica for publication.

37. C.H. Hielsen, M.S. Thesis, Cornell university (1977).

39. J. Aidelberg, Ph.D. Thesis (in preparation), Cornell Uni versity (1979).

39. C-Y. Wel and D.N. Seidman, Rad. Effects 32, 229 (1977).

40. C-Y. Wei and D.N. Seidman, J. Nuc. Mat. 69870, 693 (1978).

41. K.L. Wilson and D. 1 . Seldaan, Rad. Effects 27, 67 (1975).

42. A.S. Berger, D.M. Seidman and R. W. Belluffi, Acta Net. 21, 123 (1973).

43. A.S. Berger, D.N. Seidman and R.W. Balluffi, Acta Met. 211, 323 (1973).

44. J.Y. Park, H-C. W. Huang, A.S. Berger, and R.W. Ballufft, in Defects and Defect Clusters in B.C.C. Metals and Their Alloys, edited by R.J. Arsenault (University of Maryland, College Park, MD, 1973), Nuclear Metallurgy, Vol. 18, pp. $420-439$.

45. J.Y. Park, Ph.D. Thesis, Corneli University (1975).

46. H-C. W. Huang, Ph.D. Thesis, Cornell University (1975).

47. A. Wagner and D.N. Seidman, Phys. Rer. Letts. 42, 515 (1979).

48. A. Wagner, Ph.D. Thesis, Cornell University (1978).

49. D.N. Seidman, Department of Energy Report ffCO0-3158-77 (1979).

50. J. Aratan and D.N. Beldman, to be published. (1979).

51. A. Macrander and D.M. Seidman, unpublished work (1979).

52. M. Yamamoto and D.M. Seidnan, work in progress (1979).

53. L. A. Besvan, R.M. Scanlan and D.N. Seidman, Acta Metallurgica 19, 1339 (1971).

54. K.L. WIlson and D.N. Seidman, in Defects and Defect clusters in B.C.C. Metals and Their Alloys, edited by R.J. Arsenault (Unfverstty of Maryland, College Park, MD, 1973), Nuclear Metallurgy, Vol. 18, pp. 420-439.

55. C. Y. Wei and D.H, Seidman, Phil, Mag. A, 37, 257 (1978). 
56. C.-Y. Wei, Ph.D. Thesis, Cornell University (1978).

57. N.I. Current and D.N. SeIdman, to be published (1979).

58. S.S. Brenner and D.N. Seidman, Rad. Effects 24,73 (1975).

S9. S.S. Brenner, R. Wagner, J. Spitzmagel, Het. Trans, A, 9A, i761 (1978).

60. A. Wager and D.F. Seidman, Cornell Naterials Science Center Report $\$ 4007(1978) ;$ to appear in J. Huc. Mat. (1979).

61. C. $-Y$. Weí and D. H. Seldman, Cormell Neterials Science Center, Report \$4088 (1979).

62. Radiation-Induced Yoids in Metals, edited by J.W. Corbett and L.C. Ianniello (Hational Technical Information Service, Springfield, Va., 1972).

63. See, for example, J.Muc. Mater. $\underline{53}$ (1974), 75 (1978), and I7 (1978).

64. W.D. Wilson and C.L. Bisson, Radiat. Effects 22, 63 (1974).

65. O.S. Oen and M.T. Robinson, Nuc. Instrum. Methods 132, 647 (1976).

66. D.J. Reed, Radiat. Effects $\underline{31}, 129$ (1977).

67. B. Terresult, R.G. St-Jacques, G. Veilleaux, J.G. Mkrtel, J. L'Ecuger, C. Brassard, and C. Cardinal, Can. J. Fhys. 56, 235 (1978).

68. E.V. Kornelsen, Radiat. Effects 13, 227 (I972).

69. F. Maury, M. Biget, P. Vajda, A. Lucasson, P. Lucusson, Radiat. Effects $\underline{38}$, $53(1978)$.

70. J.P. Biersack and L.D. Haggark, submitted to Nuc. Instrum. Methods (1979).

71. I.G. Parratt, Probability end Experimental Errors in Science (John Wiley, New York, 1961), Chapt. 2.

72. J. Amano, A. Wagner and D.H. Seldman, Cornell Materials Science Center Report $\$ 4108(1979)$.

73. R.M. Scanlan, D.L. Stgris, and D.N. Seidnan, Fhilos. Mag. 23, 1439 (1971); K.L. Wilson and D.H. Seidman, Radiation Effects 27, 67 (1975); D.H. Seidman, K.L. Wilson, and C.H. Nielsen, Phys. Rev. Lett. 35, 1041 (1975). 


\section{FIGURE CAPTIOHS}

Fig. 1. (a) The in situ irradiation of a W FIM specimen with $300-\mathrm{VV}^{4} \mathrm{He}^{+}$ions at a $T_{1}$ where the implanted ${ }^{4} \mathrm{He}$ atoms are immobile. The density of spots corresponds to the approximate range profile of ${ }^{4} \mathrm{He}$ in $\mathrm{w}$. The cylindrical volume element represents the rolume chemically analyzed by the atom probe. (b) The number of 4 He atoms rersus depth as a function of $T_{1^{*}}$. Note that the ${ }^{4} \mathrm{He}$ integral profile tends to flatten out as a $T_{1}$ is increased. (c) The range profiles of ${ }^{4} \mathrm{He}$ in $W$ as a function of $T_{i}$.

Fig. 2. A schematie diagram illustrating the method employed to determine an absolute depth scale. Three states in the field evaparation of one (110) plane of $W$ are shown in (a). The field-evaporation behavior of this plane is indicated in (b) by the steplike increase in the rate at which tungsten atoms are detected.

Fig. 3. The ${ }^{3}$ He integral profiles for the inplantation energies of 100,500 and $1500 \mathrm{eV}$. The tungsten specimens were implanted to $60 \mathrm{~K}$ parallel to the [110] direction:

Fig. 4. A composite ${ }^{3}$ He range profile for all the 300 eV implantations at $60 \mathrm{~K}$. A total of $385{ }^{3}$ He events were involved in the construction of this range profile.

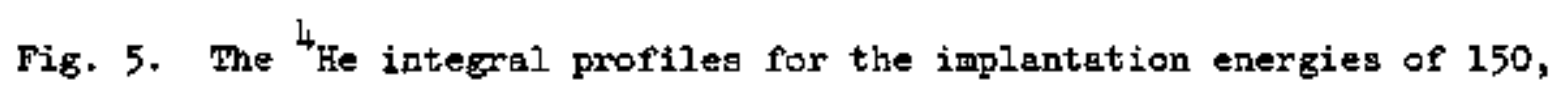
(475 and 500$)$, and $1000 \mathrm{eV}$. The tungsten specinens were implanted at 60 K parallel to the [110] direction.

Fig. 6. A composite ${ }^{4} \mathrm{He}$ range profile for all the $1000 \mathrm{eV}$ implantations at $60 \mathrm{~K}$. A total of $147^{4}$ He events were recorded in the construction of this range profile. 
Fig. T. The mean range $(\bar{x})$ in engstroms versus the incident helium energy (eV) for all the ${ }^{3} \mathrm{He}$ and ${ }^{4} \mathrm{He}$ implantations in tungsten at $60 \mathrm{~K}$.

Fig. 8. The standard deviation or straggling in angstroms $(\Delta x)$ versus the incident helium enerby (ev) for all the ${ }^{3}$ He and 4 He implantations in tungsten at $60 \mathrm{k}$.

Fis. 9. The relative variance $\left[(\Delta x)^{2} /(\bar{x})^{2}\right]$ versus the incident helium energy (ev) for all the ${ }^{3}$ He and ${ }^{4} \mathrm{He}$ impiantations in tungsten at $60 \mathrm{~K}$.

Fig. 10. The diffusion coefficient of ${ }^{3}$ He versus (1/T) in the temperature range 90 to $110 \mathrm{~K}$. The times indicated correspond to different recovery times at each temperature. 

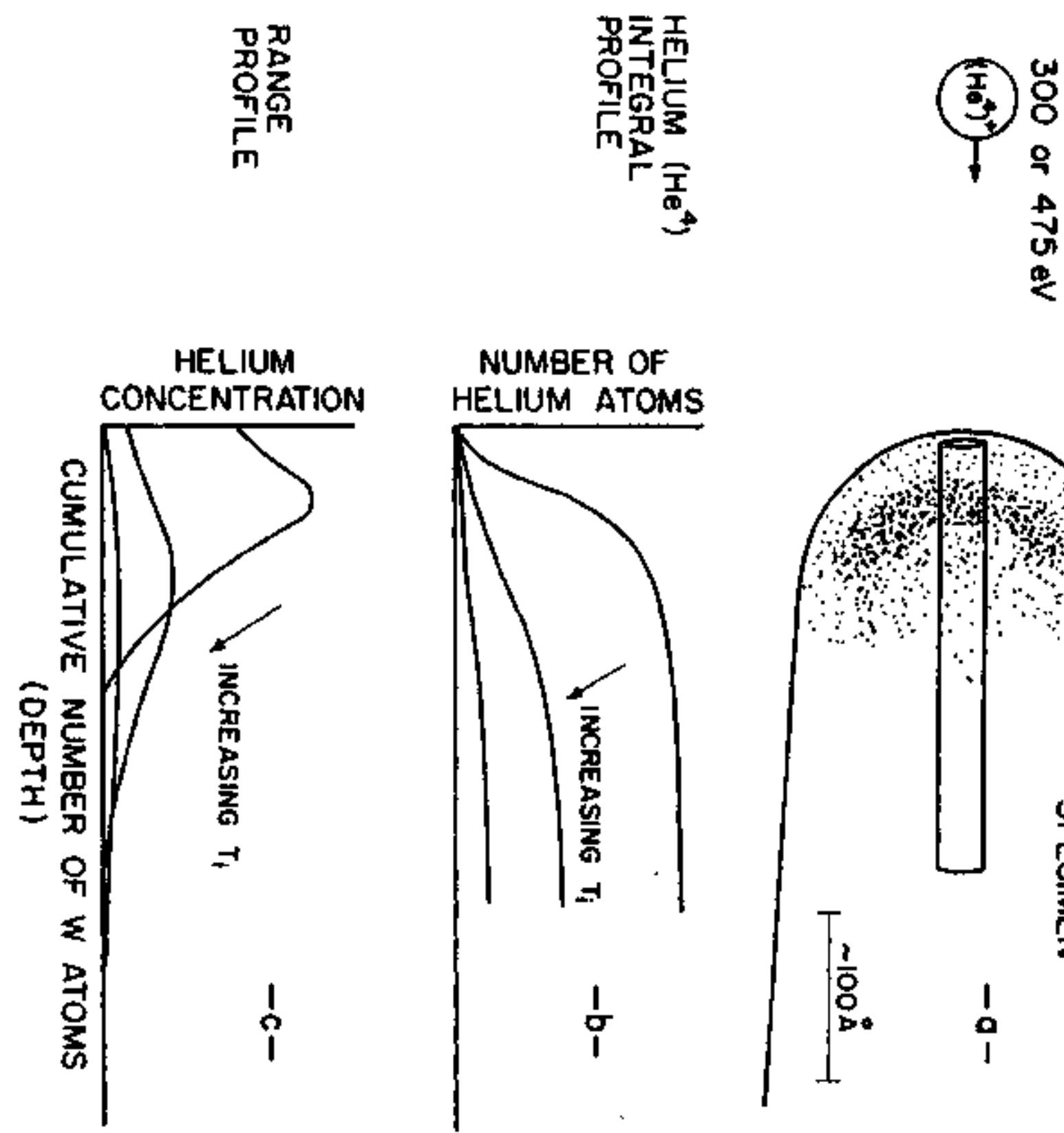

NUMEER OF

\section{HELIUM ATONS}

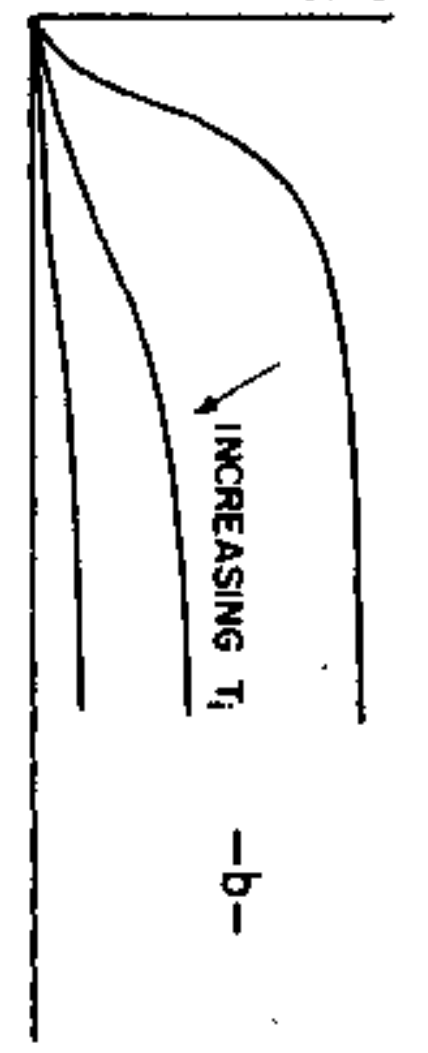

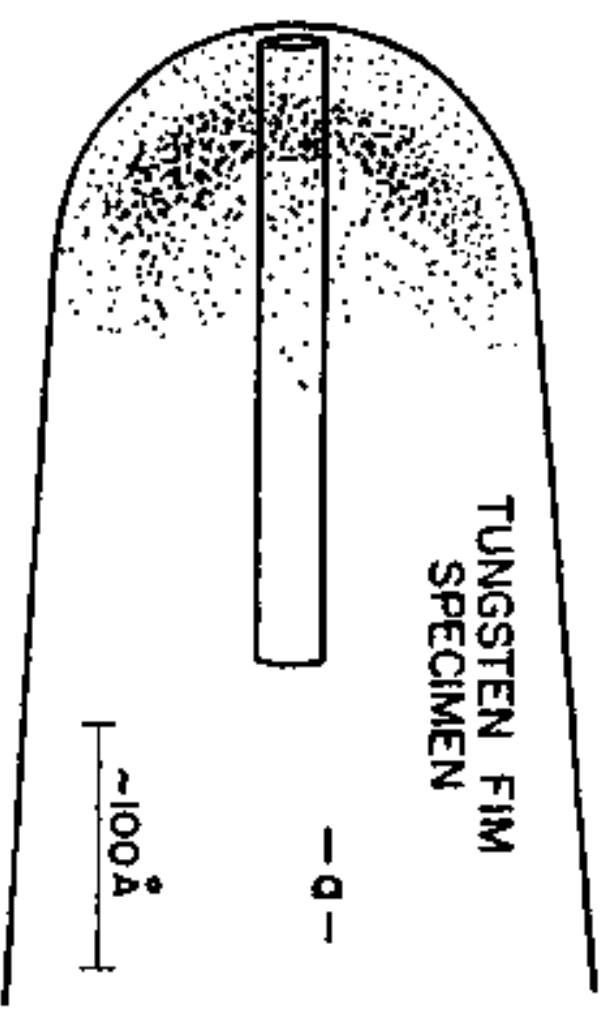


FIM SPECIMEN

PROBE HOLE ION DETECTOR

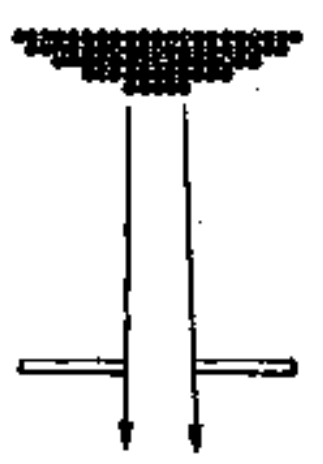

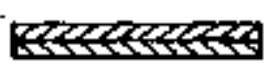

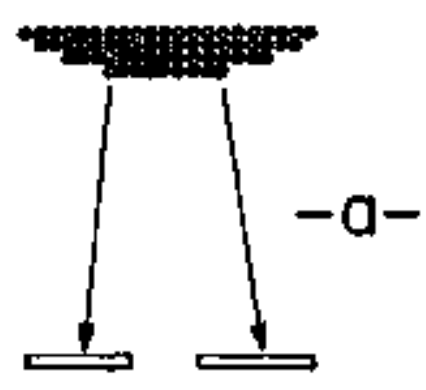

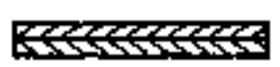

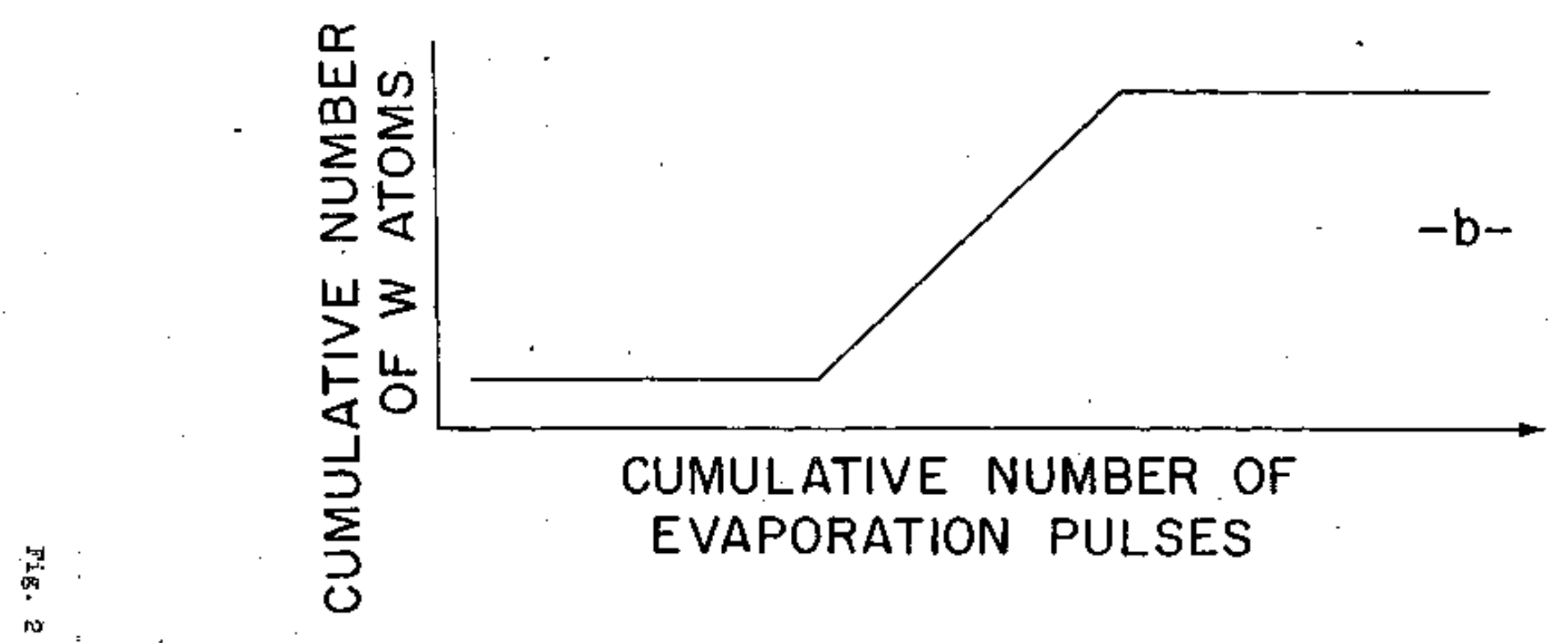




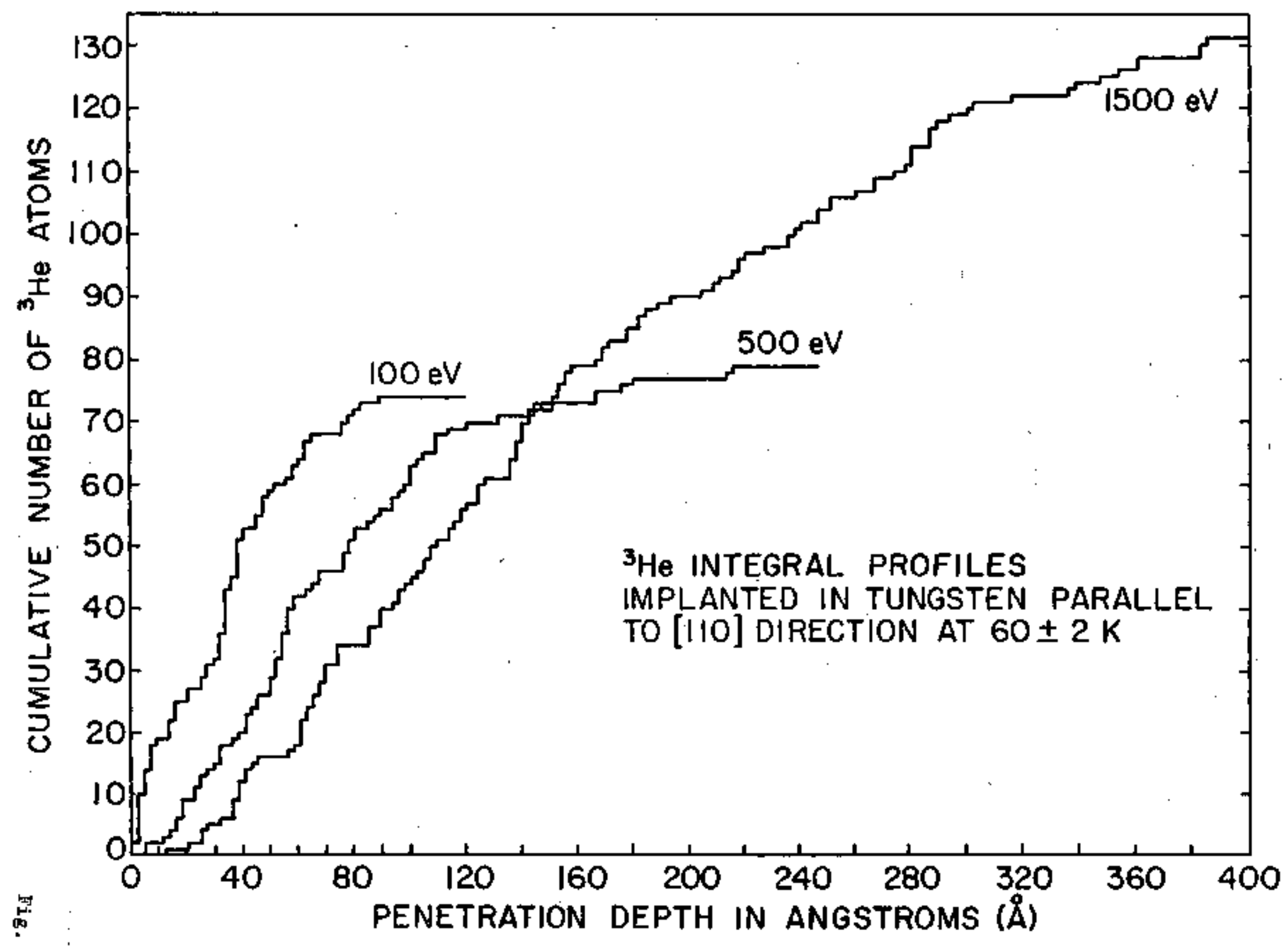




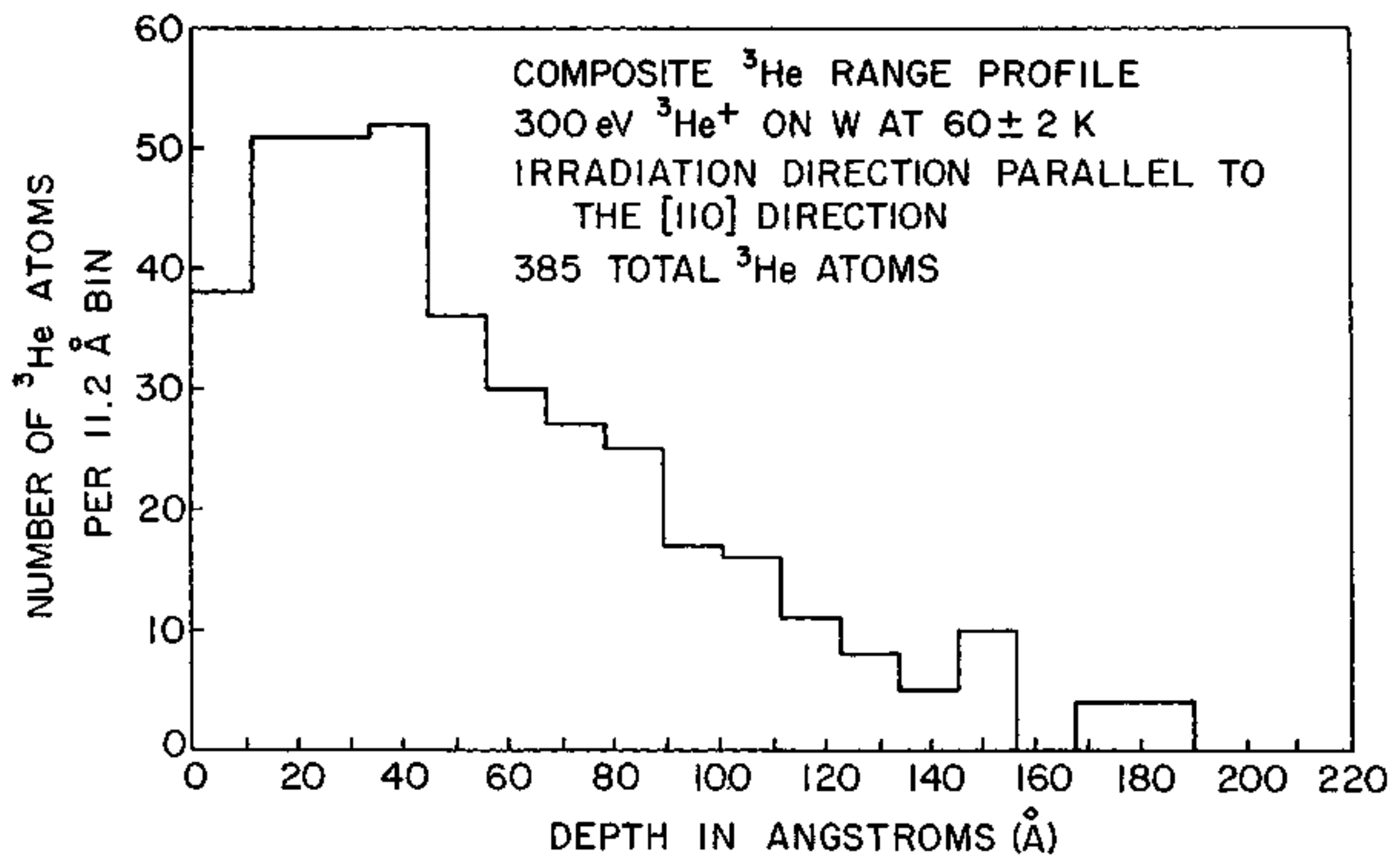

嫼 


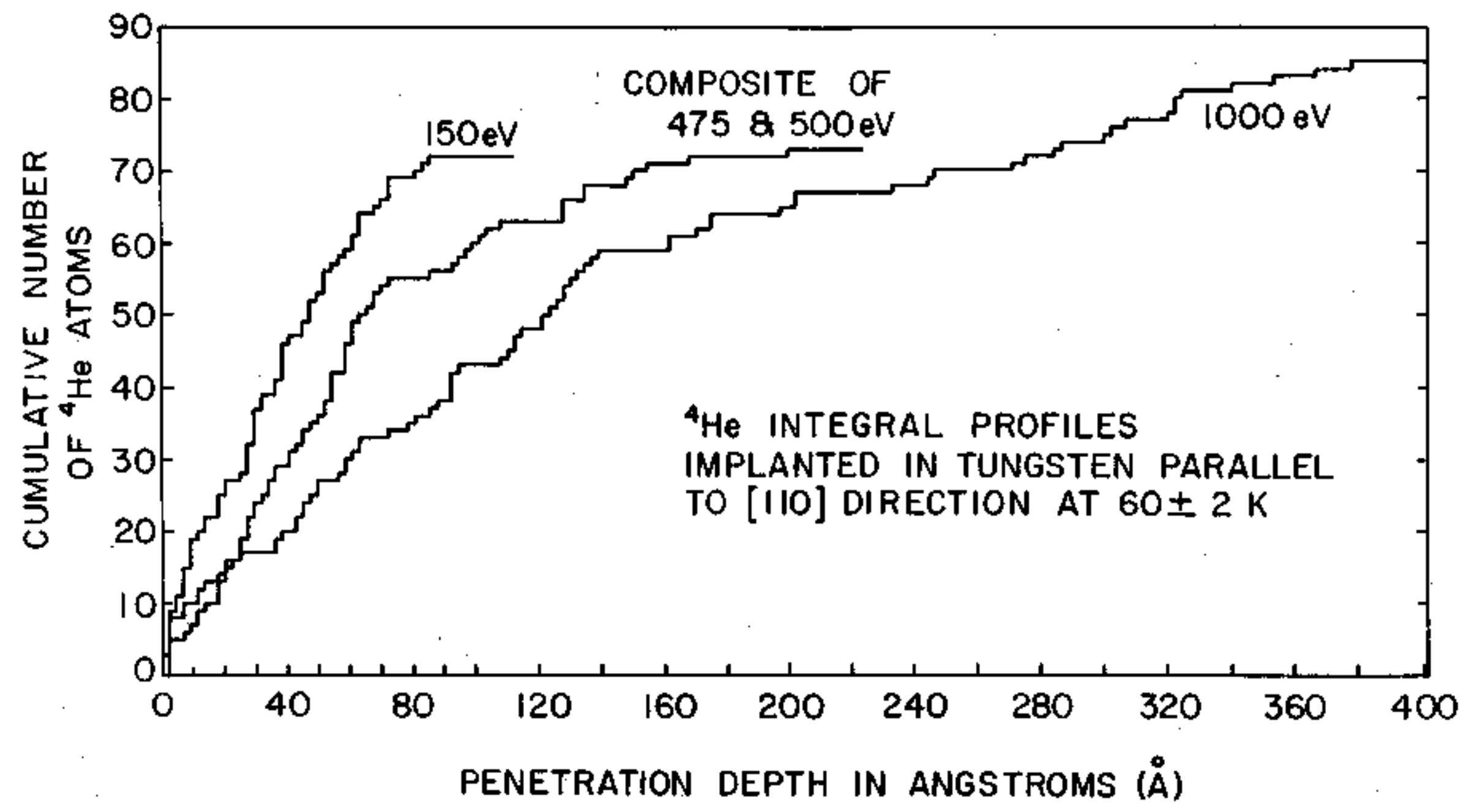

恕 


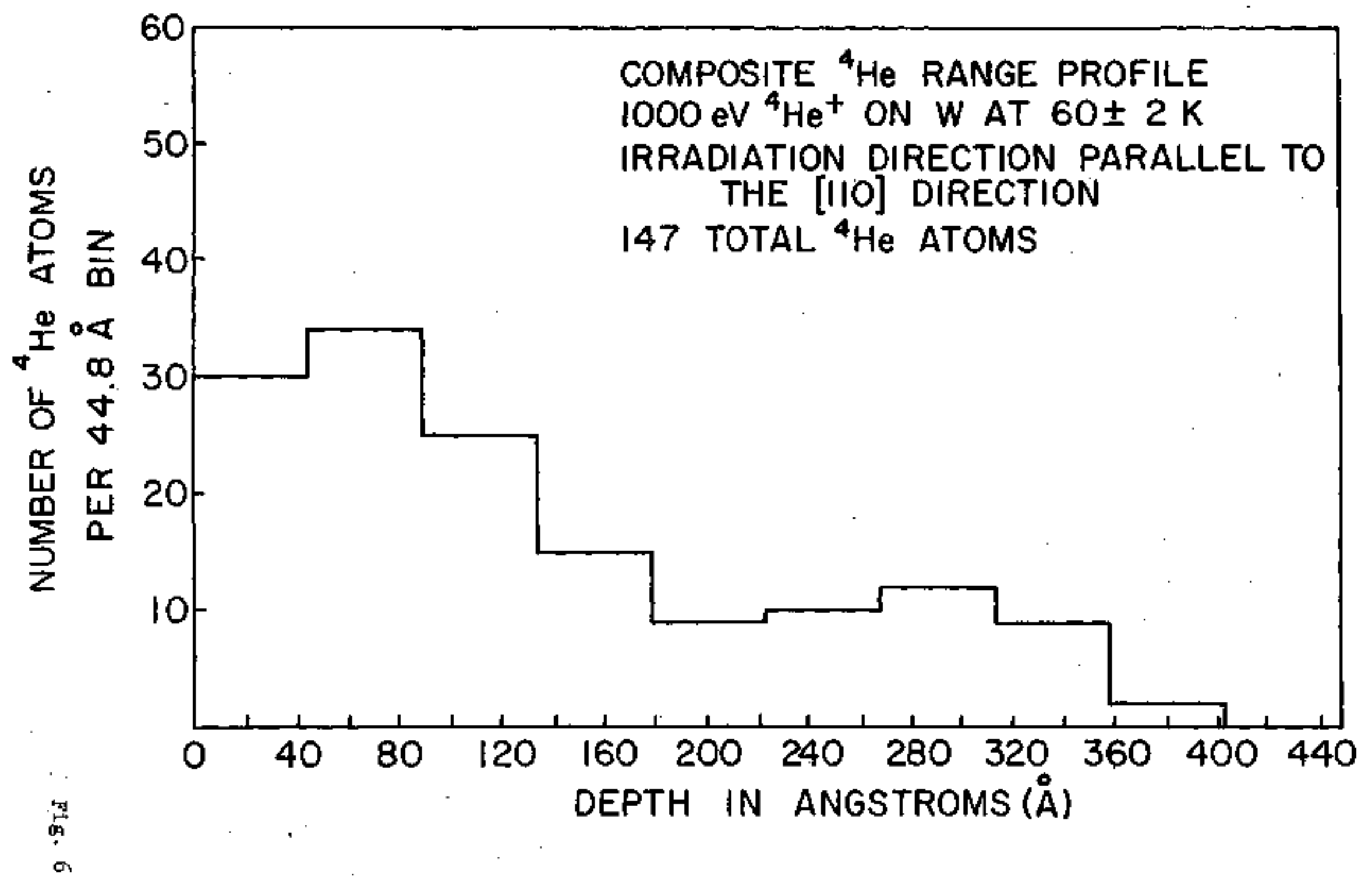




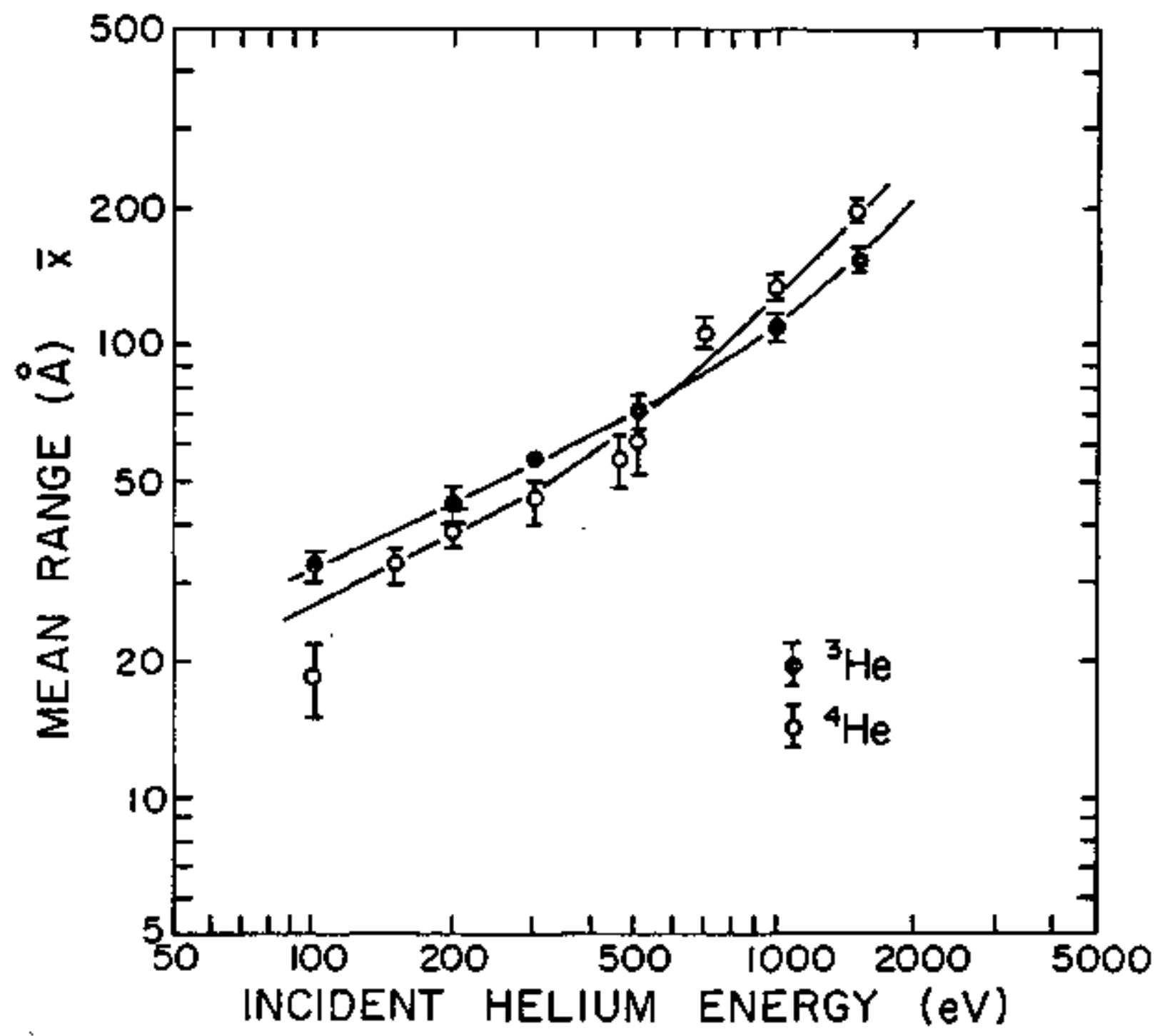

Fig. 7 


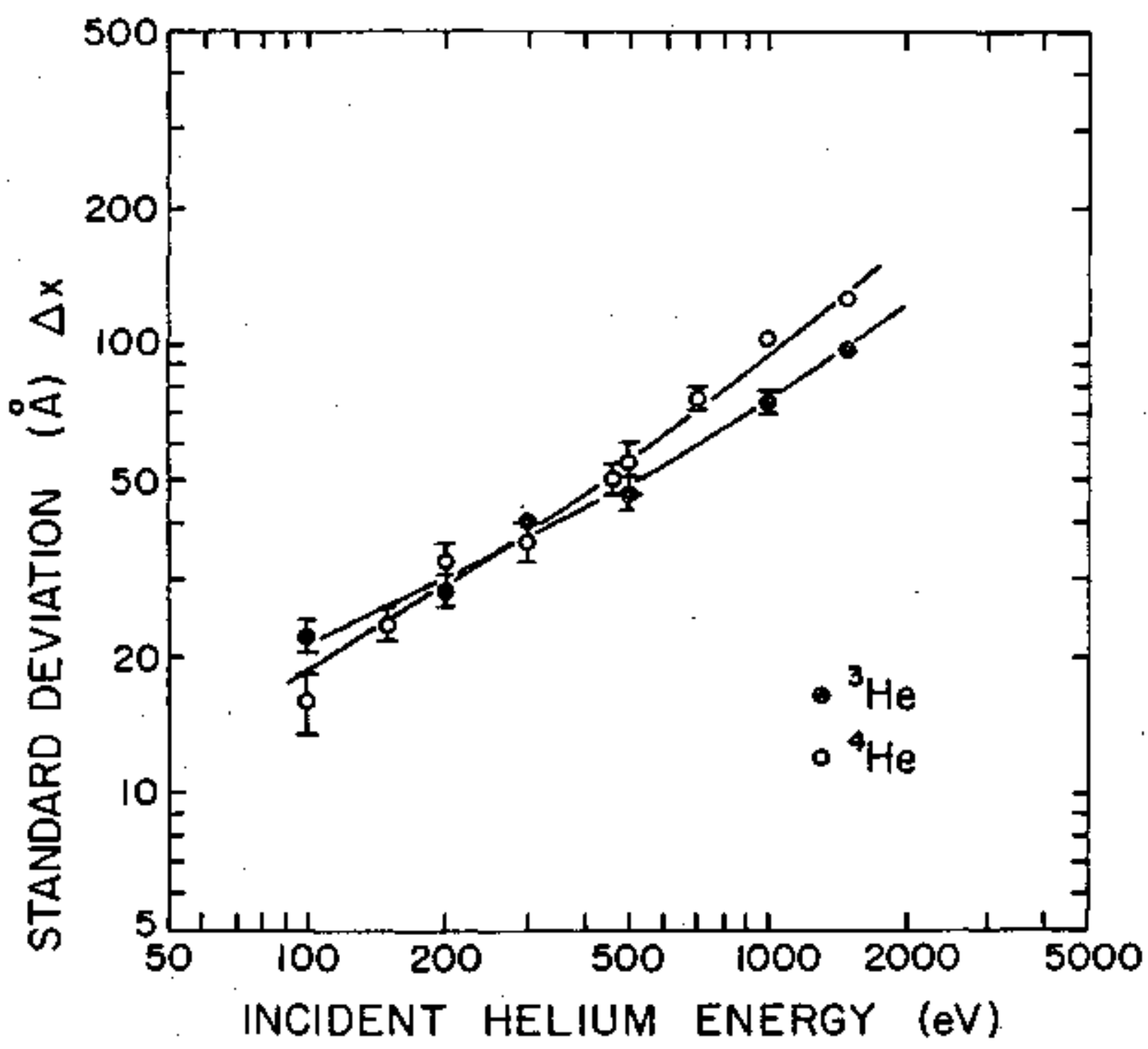

Fis. 8 


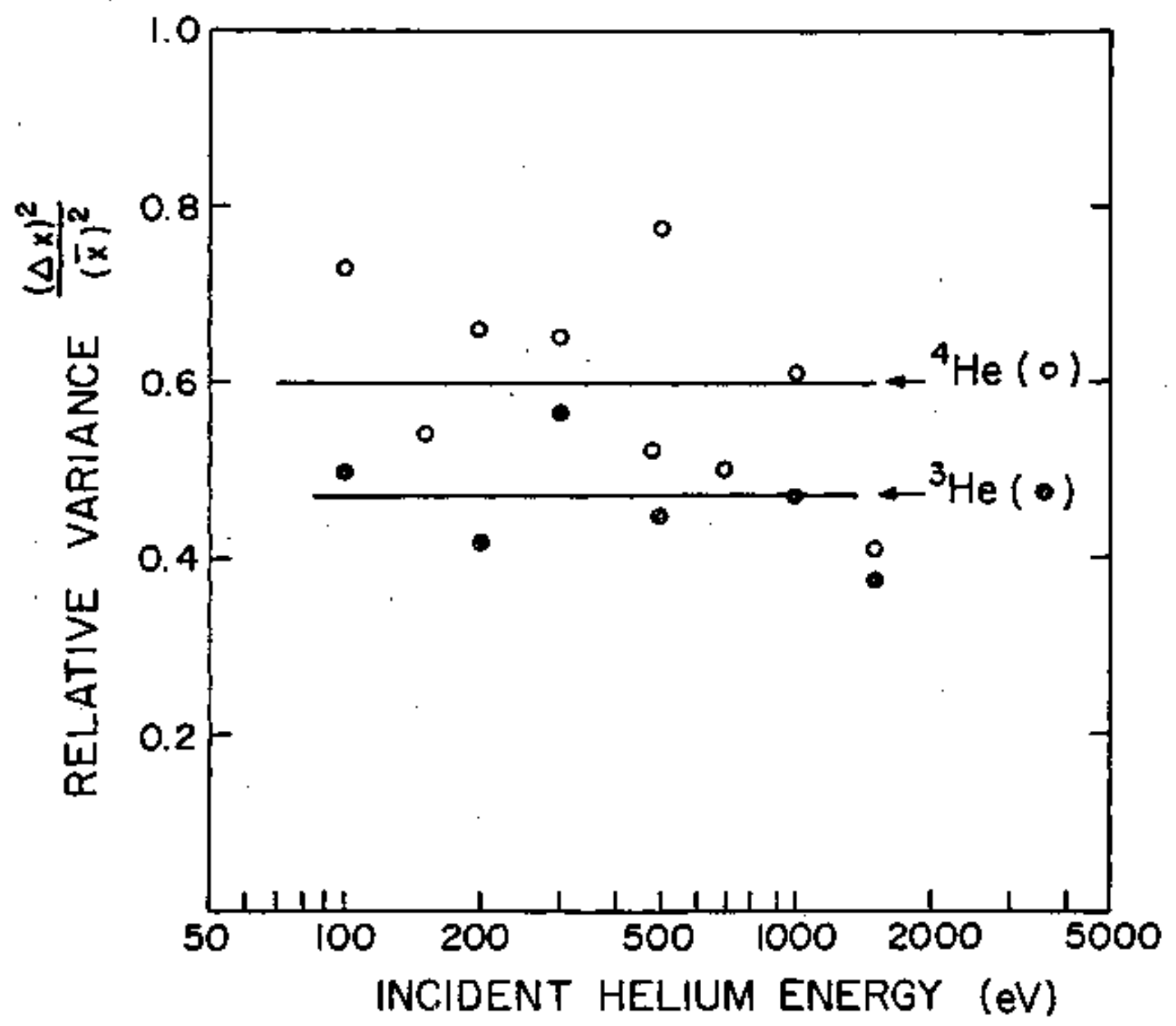

Fig. 9 


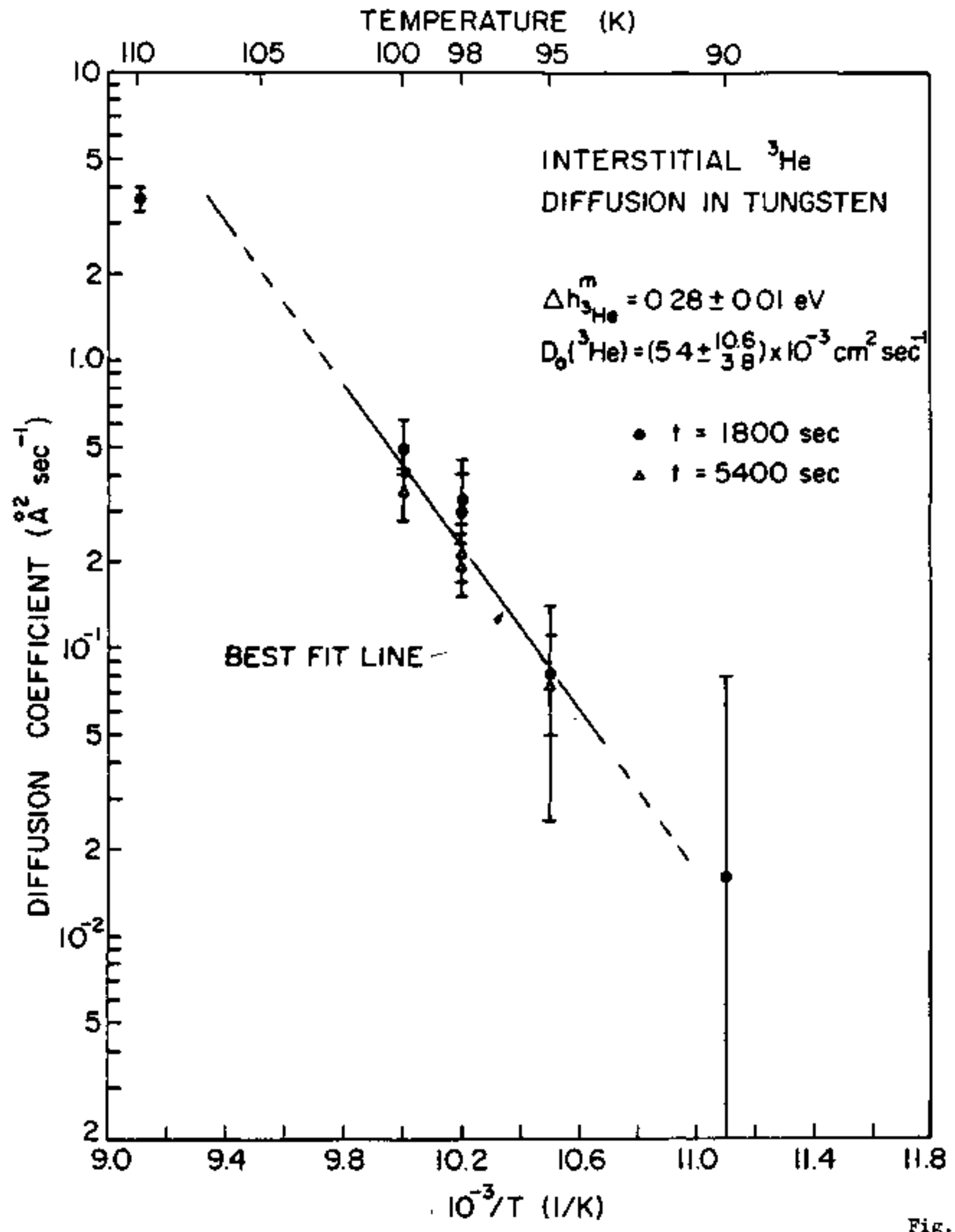

Fig. 10 